\title{
Long - term performance evaluation of a fixed and solar follow - up systems with modified astronomical positioning in Polish conditions
}

\author{
Artur Bugała', Grażyna Frydrychowicz - Jastrzębska ${ }^{1}$, Zbyszek Zbytek² $^{2}$ Jacek Dach $^{3}$, Damian Janczak ${ }^{3}$ \\ ${ }^{1}$ Institute of Electrical Engineering and Electronics, Poznan University of Technology, Poznań, Poland \\ ${ }^{2}$ Industrial Institute of Agricultural Engineering, ul. Starolecka 31 60-963 Poznan, Poland \\ ${ }^{3}$ Institute of Biosystems Engineering, Poznan University of Life Sciences, Poznań, Poland
}

\begin{abstract}
The paper presents a physical construction of a measurement stand consisting of a photovoltaic module operating in a fixed optimal configuration and in a solar tracking with a modified astronomical positioning. In order to reduce the electric energy consumption by two direct current linear motors system is positioned three times a day during winter months. Prepared energy balance, using annual measurements, confirmed the legitimacy of using two axis Sun tracking units for central Poland. Basing on the daily and monthly electricity production and solar irradiance for both photovoltaic units a mathematical formula with proposed correction factors is presented to calculate with good accuracy monthly electric energy generation for a fixed photovoltaic installation. The results of calculations were compared with measurements showing good correlation.
\end{abstract}

\section{Introduction}

The efficiency of photovoltaic conversion depends, on the one hand, on parameters of the receiver, on the other on the availability of solar radiation on its surface. It is possible to increase the amount of solar radiation on the surface of the receiver. Its value is determined by external factors like: geographical location of the PV module, the period of operation (during the day and year) and meteorological conditions, particularly cloud cover and composition of the atmosphere described by a transparency factor as well as random shading of photovoltaic cells.

Negative impact of most external conditions can be reduced by choosing appropriate spatial orientation of the receiver, including azimuth and elevation angle to the ground. The simulation carried out for Belgrade (444ㄱ $\mathrm{N})$, with similar latitude to Poznań $\left(52^{\circ} 25^{\prime} \mathrm{N}\right)$, where four different seasonal and two different biannual scenarios were considered, has shown that monthly, seasonal and yearly tilt angle optimization leads to an increase of electric energy from photovoltaic modules by $15,42 \%, 13,55 \%$ and 5,98\%, respectively [1].

Among many works available in the literature, concerning the legitimacy of using various types of Sun tracking systems, exist mainly those relating to uniaxial horizontal or vertical systems, considered as units with less complexity. The problem of a single axis positioning of the photovoltaic modules was analyzed in publications $[2,3,4,5,6]$, where authors presented different projects and executions of the follow - up systems for different geographical locations. The investigation conducted by $\mathrm{G}$.
C. Lazaroiu et al. [7] using a fixed and single - axis Sun tracker, during May and June 2014, showed the increase by $12 \%-20 \%$ of the produced energy by using the Sun tracker. The growth is maximized during "clear sky" and the ending hours of the day.

The analysis of selected works allows to state that increased complexity in the design and implementation of dual - axis control algorithm affect the growth of the electric power generation $[8,9]$, compared to systems with low complexity level [10].

The comparison of two - axis follow - up and fixed systems, performed in AGH Laboratory of Automation, Robotics, and Photovoltaic Systems (Cracow, Poland), showed that azimuth and elevation angle adjustment, in the range of $0^{\circ}-350^{\circ}$ and $0^{\circ}-70^{\circ}$, leads to $35 \%$ increase in electric energy during the year $[11,12]$.

In the foreign literature there are a few publications comparing two - axis trackers and fixed units in a different time scale, e.g. for Texas (USA) [13], for Denizli [14] and Kahramanmaras (Turkey) [15], Almaty (Kazakhstan) [16], Gwangju (South Korea) [17], Montreal (Canada) [18], Bengaluru (India) [19].

In $2013 \mathrm{Ch}$. Okoye and S. Abbasoglu presented the results of measurements of electric energy generated by three photovoltaic modules in fixed (inclination angle $\beta=$ $\left.36^{0}\right)$, horizontal $\left(\beta=0^{0}\right)$ and two - axis tracking configurations. In case of using mobile construction the highest percentage energy gain, comparing to fixed installation, was recorded for June $(58 \%)$, the lowest for January $(28 \%)$ [20].

The influence of cloud cover and the contribution of the diffuse solar radiation on the electrical parameters of 
solar cells in high latitudes (Montreal, Canada) was investigated by G. Quesada et al. [21], showing that some tracking strategies can lead to decrease in electric energy production up to $25 \%$, comparing to fixed and horizontal panels, especially on cloudy days.

A limited number of publications, describing the legitimacy of using 2 - axis Sun tracking systems for Polish climatic conditions (Central Europe), where the contribution of diffuse radiation in total solar radiation reaches even $70 \%$, forces to present long - term measurements in order to perform complete energy and economic balance, that is also common and important in case of other renewable sources of energy like biogas [22][23].

\section{Two - axis follow - up system}

A two - year comparative analysis of the operation of a photovoltaic system consisting of a polycrystalline PV module in a stationary and 2 - axis Sun tracking configuration was performed using a measurement stand showed in figure 1 .

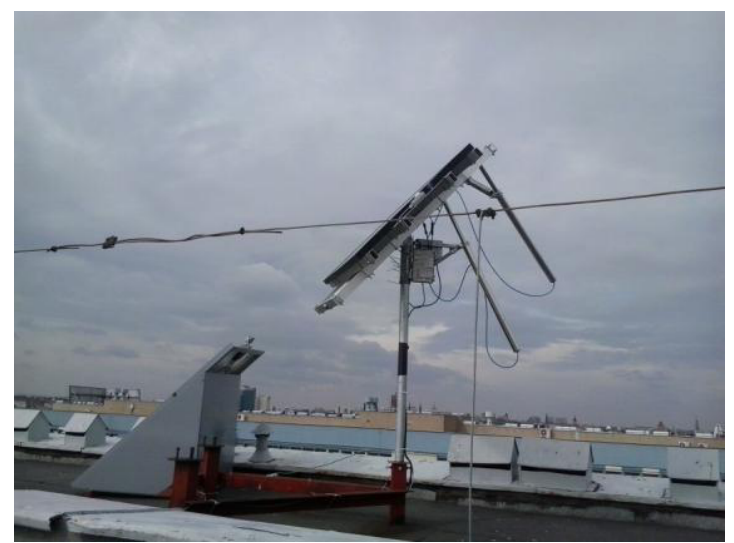

Figure 1. A photovoltaic system consisting of the fixed and the 2 - axis tracking construction.

Table 1 presents the parameters of the single photovoltaic module and DC/AC microinverter used in the comparative analysis.

Table 1. Parameters of the photovoltaic modules and microinverters

\begin{tabular}{|c|c|c|c|}
\hline $\begin{array}{c}\text { Photovoltaic } \\
\text { module }\end{array}$ & Value & $\begin{array}{c}\text { DC/AC } \\
\text { converter }\end{array}$ & Value \\
\hline Maximum power & $210 \mathrm{~W}_{\mathrm{p}}$ & $\begin{array}{c}\text { Nominal input } \\
\text { power }\end{array}$ & $240 \mathrm{~W}$ \\
\hline $\begin{array}{c}\text { Voltage at max. } \\
\text { power point }\end{array}$ & $29.64 \mathrm{~V}$ & $\begin{array}{c}\text { Maximum DC } \\
\text { voltage }\end{array}$ & $44 \mathrm{~V}$ \\
\hline $\begin{array}{c}\text { Current at max. } \\
\text { power point }\end{array}$ & $6.98 \mathrm{~A}$ & $\begin{array}{c}\text { Minimum DC } \\
\text { voltage }\end{array}$ & $20 \mathrm{~V}$ \\
\hline $\begin{array}{c}\text { Open circuit } \\
\text { voltage }\end{array}$ & $35.94 \mathrm{~V}$ & $\begin{array}{c}\text { Range of } \\
\text { MPPT }\end{array}$ & $23 \mathrm{~V}-35 \mathrm{~V}$ \\
\hline Short circuit current & $7.6 \mathrm{~A}$ & $\begin{array}{c}\text { Maximum } \\
\text { input current }\end{array}$ & $12 \mathrm{~A}$ \\
\hline
\end{tabular}

In the project the magnetic incremental encoders are used to describe the current position of the solar receiver in a horizontal and vertical axis. Two Hall sensors measure the voltage at the electrode terminals perpendicular to the magnetic field line. The current magnet displacement is correlated with the magnetic field intensity. The resolution of used direct current linear motors is $380 \mathrm{imp} . / \mathrm{mm}$. The control unit used in the tracking system allows to connect external sensors e.g. to measure the wind speed and direction, snow cover, temperature or weight on the photovoltaic module plane. In the case of high wind speed the solar receiver is positioned to horizontal position. Snow coverage implies vertical position with the inclination angle to the ground $\beta=90^{\circ}$, which allows to reduce the shading effect.

In order to determine the incidence angle of solar radiation on a plane tilted at $\beta$ angle to the ground, a relationship between vector a $\left\{a_{x}, a_{y}, a_{z}\right\}$ - perpendicular to the surface of the photovoltaic module - and $\mathbf{b}\left\{b_{x}, b_{y}\right.$, $\left.b_{z}\right\}$ - identical with direct solar radiation - should be described. A scalar product of two vectors equals $\cos \theta$.

A unit vectors can be determined using relationships (1) - (3) [24]:

$$
\begin{array}{cc}
a_{x}=\cos \alpha \cos \beta & b_{x}=\cos \alpha^{\prime} \cos \beta^{\prime} \\
a_{y}=\sin \alpha \cos \beta & b_{y}=\sin \alpha^{\prime} \cos \beta^{\prime} \\
a_{z}=\sin \beta & b_{z}=\sin \beta^{\prime}
\end{array}
$$

where: $\alpha, \beta-$ azimuth and inclination angle of the photovoltaic module, $\alpha^{\prime}-$ Sun azimuth angle, $\beta^{\prime}-$ Sun elevation angle.

Sun elevation and azimuth angle are defined by the relation [24]:

$$
\beta^{\prime}=\arcsin (\sin \varphi \sin \delta+\cos \varphi \cos \delta \cos \omega)
$$

$$
\alpha^{\prime}=\arcsin \left(\frac{\cos \delta \sin \omega}{\cos \beta^{\prime}}\right)
$$

Taking into account equations (1) - (5) formula describing the incidence angle of solar radiation on a plane tilted at $\beta$ angle to the ground has the following form [25]:

$$
\begin{aligned}
& \cos \theta=\sin \delta \sin \varphi \cos \beta-\sin \delta \cos \varphi \sin \beta \cos \gamma+ \\
& +\cos \delta \cos \varphi \cos \beta \cos \omega+\cos \delta \sin \varphi \sin \beta \cos \gamma \cos \omega+ \\
& +\cos \delta \sin \beta \sin \gamma \sin \omega
\end{aligned}
$$

For considered spatial orientation (photovoltaic module plane is facing south) the relation (6) can be expressed by the following formula:

$$
\cos \theta=\sin \delta \sin (\varphi-\beta)+\cos \delta \cos (\varphi-\beta) \cos \omega
$$

Time between the local noon and the sunrise $\left(H_{s r}\right)$ and sunset $\left(H_{s s}\right)$ were calculated using formula [26]:

$$
H s r=-H s s=\arccos (-\tan \varphi \tan \delta) / 15
$$

The hour of the day when the Sun reaches its highest altitude can be described using the relation [27]: 


$$
\begin{aligned}
& L N=12: 00-\{229,2\{0,000075+0,00187 \cos \omega- \\
& +0,03208 \sin \omega-0,0146 \cos 2 \omega- \\
& +0,0409 \sin 2 \omega\}\} / 60
\end{aligned}
$$

Local time $L T$ for an analyzed longitude can be expressed by the following relation [26]:

$$
L T=G M T+\text { Long. } / 15
$$

where: GMT - Greenwich Mean Time, moment the Sun crosses the Greenwich meridian.

\section{Stationary photovoltaic configuration}

Fixed photovoltaic unit, analyzed with 2 - axis follow up construction, consists of polycrystalline module installed with calculated elevation angle $\beta=37^{\circ}$ in south direction. The Liu - Jordan isotropic model, which describes solar radiation on tilted surface using direct and diffuse radiation for a horizontal plane, was used to determine the elevation angle [25]:

$$
\begin{gathered}
G_{\beta}=G_{b} \cdot \frac{\sin \delta(t) \cdot[\sin \varphi \cdot \cos \beta-\cos \varphi \cdot \sin \beta \cdot \cos \gamma]}{\sin \delta(t) \cdot \sin \varphi+\cos \delta(t) \cdot \cos \varphi \cdot \cos \omega(t)}+ \\
\frac{\cos \delta(t) \cdot\left[x_{0}(\varphi, \beta, \omega)+x_{1}(\varphi, \beta, \gamma, \omega)+x_{2}(\beta, \gamma, \omega)\right.}{\sin \delta(t) \cdot \sin \varphi+\cos \delta(t) \cdot \cos \varphi \cdot \cos \omega(t)}+ \\
+G_{d} \cdot\left(\frac{1+\cos \beta}{2}\right)+\left(G_{b}+G_{d}\right) \cdot \rho_{o} \cdot\left(\frac{1-\cos \beta}{2}\right) \\
x_{0}=\cos \varphi \cdot \cos \beta \cdot \cos \omega(t) \\
x_{1}=\sin \varphi \cdot \sin \beta \cdot \cos \gamma \cdot \cos \omega(t) \\
x_{2}=\sin \beta \cdot \sin \gamma \cdot \sin \omega(t)
\end{gathered}
$$

where: $G_{b}, G_{d}$ - direct and diffuse solar radiation for a horizontal surface; $G_{\beta}$ - total solar radiation for a plane tilted at $\beta$ angle; $\varphi$ - latitude angle; $\delta(t)$ - declination angle; $\omega(t)$ - hour angle; $\rho_{o}$ - reflectance factor.

The calculations were conducted using Matlab simulation software. The aim was to verify the total value of radiation power density in a one - degree step. For each new value of the $\beta$ angle, the insolation value was determined for particular hours and was added on a daily and yearly basis to a two - dimensional array. The calculations were repeated until the highest value corresponding to the amount of electricity was obtained. The values of total, direct and diffuse solar radiation at selected spatial orientations were obtained from a typical metrological year TMY2 for the city of Poznań (Poland) [28].

\section{Results}

The two - year measurements of electric power and cumulative energy, AC voltage and current, irradiance and insolation on a photovoltaic module plane in a stationary and follow - up configuration were conducted in natural solar radiation.

The value of electric energy produced by a photovoltaic module, dependent on the registered insolation, efficiency of a photovoltaic conversion, area of a PV module and value of electric energy losses (e.g. temperature losses, shading effect) may be defined by the relation:

$$
E_{r z}=E \cdot S \cdot \eta \cdot \frac{100 \%-\sum P_{S \%}}{100 \%}
$$

where: $E$ - insolation on a horizontal photovoltaic module plane, $S$ - area of a PV module plane, $P_{s \%}-$ power losses in analyzed system, $\eta$ - efficiency of a photovoltaic conversion.

A modified relationship, presented in a general form in [29], describing monthly electric energy production by a fixed photovoltaic unit, using determined correction factors for Polish climatic conditions presented in table 2, has the following form:

$$
E_{r z, \text { fixed }}=\left(\sum_{i=1}^{12} E_{f i x, i} \cdot k_{i}\right) \cdot P_{m} \cdot\left[1-\frac{1}{100}\left(\sum P_{s \%}\right)\right]
$$

where: $E_{f i x}$ - insolation on a fixed photovoltaic module plane, $P_{m}$ - maximum power of a photovoltaic module, $k_{i}$ - average value of determined correction factor.

In addition, monthly electric energy produced by a $2-$ axis Sun tracker has been described using a modified formula [30]:

$$
E_{r z, t r a c k}=n \cdot \sum_{i=1}^{i=12} E_{t r, i} \cdot \sum P_{s} \cdot P_{o c, s c} \cdot F F \cdot\left|1-\frac{1}{\sum P_{s}}\right|
$$

where: $E_{t r}$ - insolation on a 2 - axis tracking plane, $n-$ number of PV modules, $P_{o c, s c}-$ apparent power, $F F$ - fill factor.

Results of measurements, conducted between July 2014 and June 2015, were compared with values determined using formula (16) and (17).

On the basis of a thirty - second measurements of irradiance, conducted by means of prepared microprocessor system and a silicon sensor, monthly insolation $E_{f i x}$ and $E_{t r}$ was determined on a photovoltaic module plane in a fixed and tracking configuration. 
Average correction factors calculated for 12 months of the year, on the basis of 24 - month measurements conducted between 07.2013 - 06.2015, describe the relationship between monthly electric energy generated by a photovoltaic module in a fixed configuration and value determined using general formula (15), for central Poland.

Table 2 presents calculated correction factors of monthly electric energy for a fixed photovoltaic unit.

Table 2. Correction factors of the electric energy determined on the basis of 24 - month measurements

\begin{tabular}{|c|c|c|c|c|c|c|}
\hline Month number & I & II & III & IV & V & VI \\
\hline Value & 0.93 & 0.93 & 0.83 & 0.87 & 0.88 & 0.84 \\
\hline Month number & VII & VIII & IX & X & XI & XII \\
\hline Value & 0.73 & 0.78 & 0.93 & 0.88 & 0.77 & 0.73 \\
\hline
\end{tabular}

Figure 2 shows the value of annual electricity production for a fixed photovoltaic installation, on the basis of real measurements conducted between July 2014 - June 2015 and calculations using modified mathematical relationship (16) with relative error analysis, including determined correction factors and without correction.

Figure 3 shows the value of annual electricity production for a 2 - axis Sun tracking construction, on the basis of real measurements conducted between July 2014 - June 2015 and calculations using mathematical formula (17).

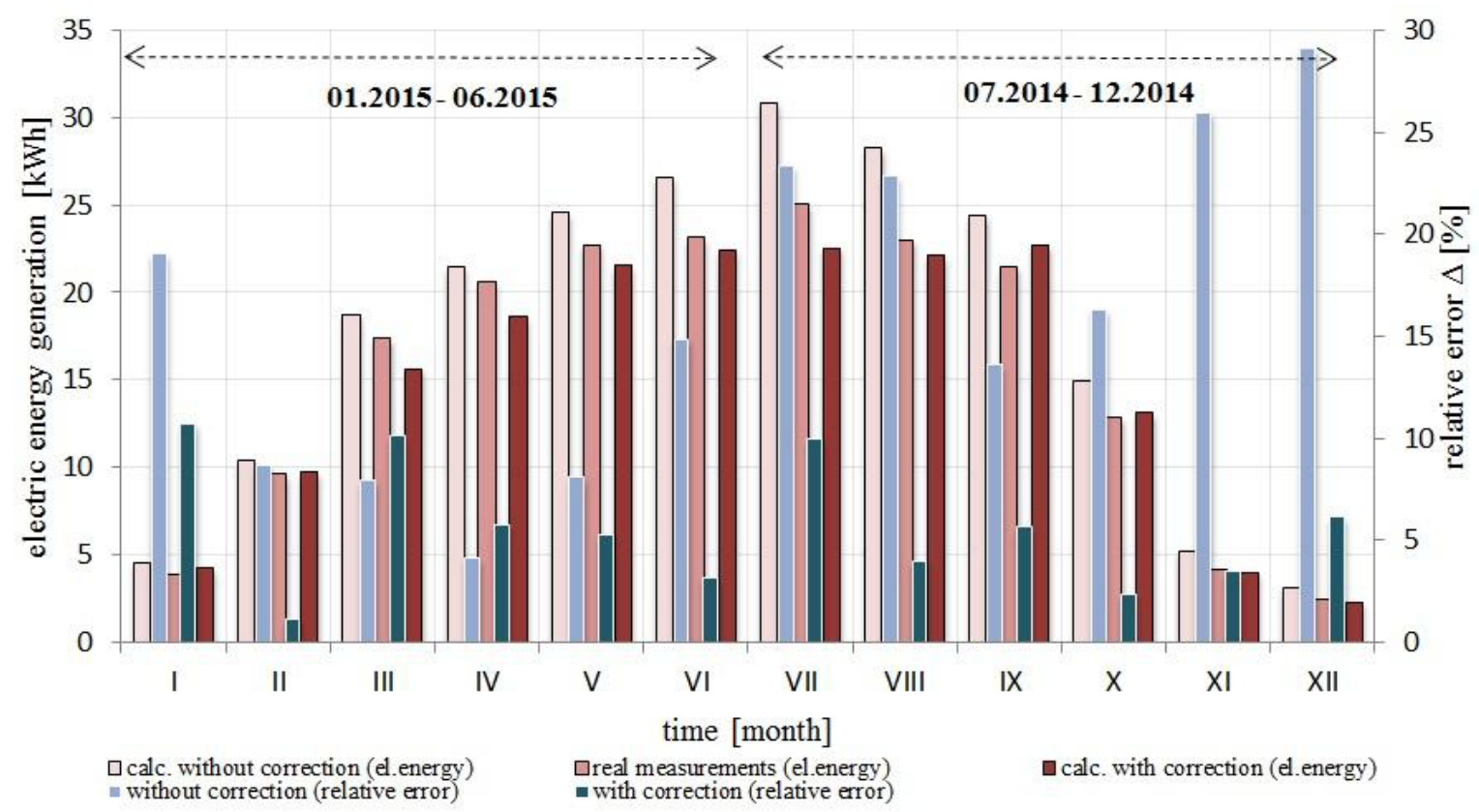

Figure 2. Energy differences between calculated without correction, with proposed monthly correction factors and measured values of electric energy for a fixed system including relative error analysis.

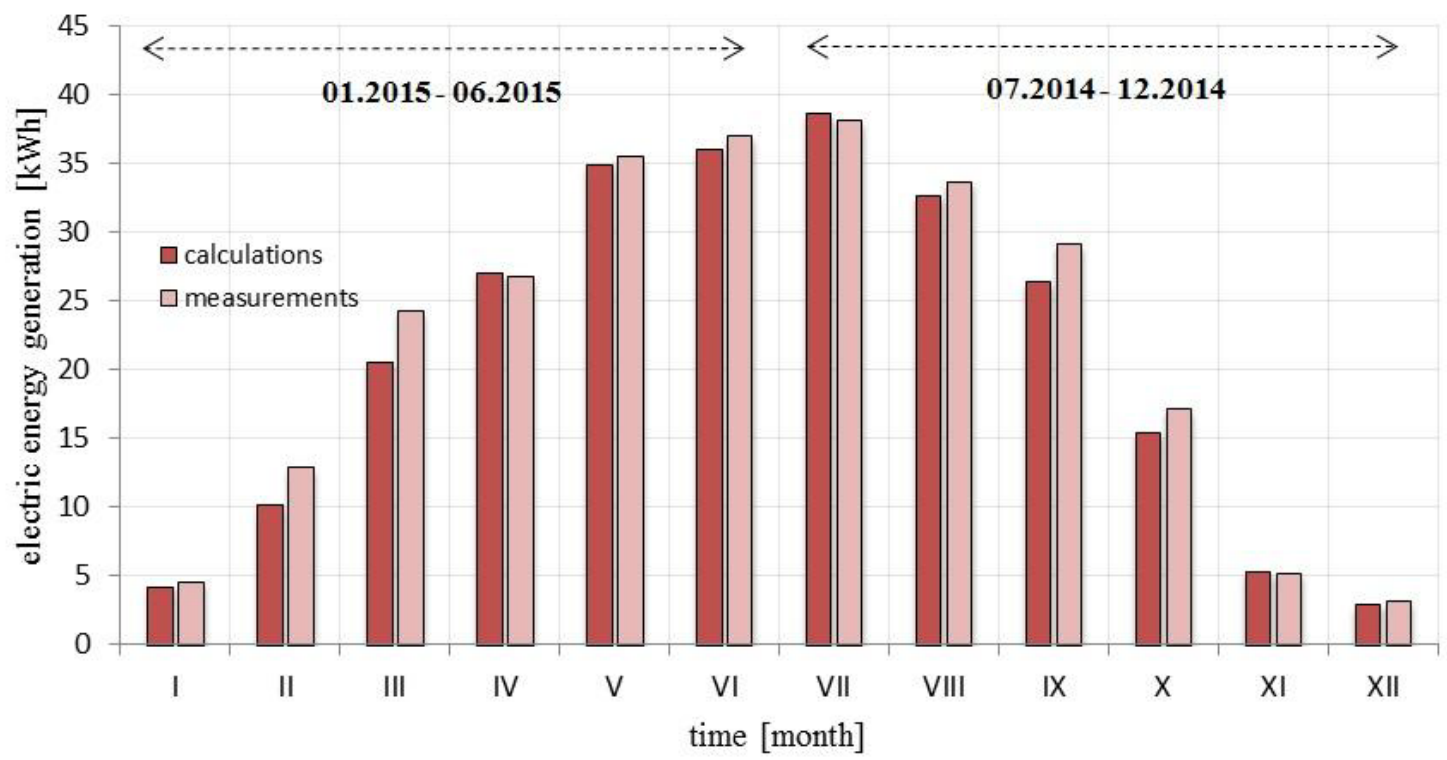

Figure 3. Energy differences between calculated and measured values of electric energy for a 2 - axis Sun tracking unit. 


\section{Discussion}

The comparative analysis for 24 months proved the legitimacy of using 2 - axis follow - up systems in photovoltaics for the climatic conditions of central Poland.

Energy gain from the proposed algorithm was $56 \%$, $61 \%, 53 \%, 47 \%, 36 \%$ and $34 \%$ gross, and $43 \%, 47 \%$, $40 \%, 32 \%, 23 \%$ and $16 \%$ net in May, June, July, August, September and October 2014, respectively.

The proposed mathematical relationship for a stationary PV system, based on the monthly insolation and the proposed 12 correction factors using 2 - year measurements, allows to estimate the value of monthly electric energy with sufficient accuracy. The application of average correction factors allowed to reduce the percentage relative error from $23.32 \%, 22.81 \%, 13.6 \%$, $16.26 \%, 25.93 \%, 29.09 \%$ to $9.92 \%, 3.95 \%, 5.64 \%$, $2.31 \%, 3.41 \%, 6.11 \%$ in July, August, September, October, November, and December 2014. The lowest value of the $\Delta \%$ parameter, in case of a fixed photovoltaic unit, was observed in February 2014, where introduced correction decreased the percentage error more than four times from $6 \%$ to $1.39 \%$. A similar situation occurs in the following measurement year, where the value of the percentage relative error $\Delta \%$, between measured and calculated amount of electric energy in February 2015 is reduced from $8.63 \%$ to $1.06 \%$, which is presented in figure 2 .

The biggest differences between a measured value of the electric energy produced by the fixed photovoltaic module, and one determined on the basis of the relation without correction, are observed in June, July and August. A high temperature of silicon solar cells during summer months, without sufficient ventilation, may cause the decrease in voltage at the maximum power point, leading to significant differences in electric energy. This situation does not occur at such a level in the case of well ventilated solar module in tracking unit (figure 3).

A mathematical formula describing monthly electric energy production by the 2 - axis follow - up unit allows high accuracy prediction using values of insolation on a surface at a particular spatial orientation and the electrical parameters of a solar module, which is confirmed in figure 3. Presented formula does not require to use correction factors.

Calculations based on the generalized mathematical relationship (15), without monthly correction, lead to significant forecast errors.

\section{References}

1. M. Despotovic, V. Nedic, Comparison of optimum tilt angles of solar collectors determined at yearly, seasonal and monthly levels, Energ. Convers. Manage. 97, 121 - 131 (2015)

2. N. Bansal, A. Chaudhari, M. Mishra, J. Jadav, Fabrication of a cost effective automatic dual/single axis active solar tracker with built in inverter designed for grid connectivity and standalone systems, IJEAT 3, 159 - 162 (2014)
3. Z. Li, X. Liu, R. Tang, Optical performance of vertical single-axis tracked solar panels, Renew. Energy 36, 64 - 68 (2011)

4. G. Li, R. Tang, H. Zhong, Optical Performance of Horizontal Single-Axis Tracked Solar Panels, Energy Procedia 16, 1744 - 1752 (2012)

5. I. Sefa, M. Demirtas, I. Colak, Application of one axis sun tracking system, Energ. Convers. Manage. 11, $2709-2718$ (2009)

6. T. Tudorache, L. Kreindler, Design of a solar tracker system for PV power plants, Acta Polytech. Hung. 1, 23 - 29 (2010)

7. G. Lazaroiu, M. Longo, M. Roscia, M. Pagano, Comparative analysis of fixed and sun tracking low power systems considering energy consumption, Energ. Convers. Manage. 92, 143 - 148 (2015)

8. B. Khadidja, K. Dris, A. Boubeker, S. Noureddine, Optimisation of a Solar Tracker System for Photovoltaic Power Plants in Saharian region, Example of Ouargla, Energy Procedia 50, 610 618 (2014)

9. H. Mousazadeh, A. Keyhani, A. Javadi, H. Mobli, K. Abrinia, A. Sharifi, A review of principle and sun - tracking methods for maximizing solar systems output, Renew. Sustainable Energy Rev. 13, 1800 - 1818 (2009)

10. Y.B. Gebremedhen, Determination of Optimum Fixed and Adjustable Tilt Angles for Solar Collectors by Using Typical Meteorological Year data for Turkey, Int. J. Renew. Energy Res. 4, 924 928 (2014)

11. J. Chojnacki, J. Teneta, Ł. Więckowski, Development of PV systems and research studies on photovoltaics at the AGH University of Science and Technology in Krakow, $22^{\text {nd }}$ European Photovoltaic Solar Energy Conference, Milan, Italy, $3-7$ September 2007, 3049 - 3052

12. J. Teneta, Ł. Więckowski, Dissemination of Polish and world achievements in photovoltaics in the education process at high level - II edition, 178 189

13. W. Grady, H. Thomas, Predicting the Impact of Panel Orientation and Tracking on PV Daily Energy Harvest, IEEE Energytech Conference, Cleveland, USA, 21 - 23 May 2013, 1 - 3

14. S. Kivrak, M. Gunduzalp, F. Dincer, Theoretical and experimental performance investigation of a two - axis solar tracker under the climatic condition of Denizli, PE. 2, 332 - 336 (2012)

15. S. Yilmaz, H. Ozcalik, O. Dogmus, F. Dincer, O. Akgol, M. Karaaslan, Design of two axes sun tracking controller with analytically solar radiation calculations, Renew. Sustainable Energy Rev. 43, $997-1005$ (2015)

16. S. Sadyrbayev, A. Bekbayev, S. Orynbayev, Z. Kaliyev, Design and Research of Dual - Axis Solar Tracking System in Condition of Town Almaty, J. Scien. Res. 17, 1747 - 1751 (2013)

17. J. Byeong - Ho, P. Ju - Hoon, K. Seung - Dai, K. Jong - Ho, Performance Evaluation of Dual Axis Solar Tracking System with Photo Diodes, International Conference on Electrical Machines 
and Systems, Busan, Korea, 26 - 29 October 2013, $414-417$

18. M. Mehrtash, G. Quesada, Y. Dutil, D. Rousse, Performance Evaluation of Sun Tracking Photovoltaic Systems in Canada, 20th Annual International Conference on Mechanical Engineering - ISME, Shiraz, Iran, 16 - 18 May 2012, $1-4$

19. R.R. Rao, H.R. Swetha, J. Srinivasan, S.K. Ramasesha, Comparison of performance of solar photovoltaics on dual axis tracker with fixed axis at $13^{\circ} \mathrm{N}$ latitude, Curr. Sci. 10, 2087 - 2093 (2015)

20. Ch. Okoye, S. Abbasoglu, Empirical investigation of fixed and dual axis Sun tracking photovoltaic system installations in Turkish Republic of Northern Cyprus, J. Asian Scien. Res. 5, 440 - 453 (2013)

21. G. Quesada, L. Guillon, D. Rousse, M. Mehrtash, Y. Dutil, P. Paradis, Tracking strategy for photovoltaic solar systems in high latitudes, Energ. Convers. Manage. 103, 147 - 156 (2015)

22. J. Dach, P. Boniecki, J. Przybył, D. Janczak, A. Lewicki, W. Czekała, K. Witaszek, P.C. Rodríguez Carmona, M. Cieślik, Energetic efficiency analysis of the agricultural biogas plant in $250 \mathrm{kWe}$ experimental installation, Energy 69, 34 - 38 (2014)

23. W. Czekała, K. Kozłowski, J. Dach, P. Boniecki, A. Lewicki, D. Janczak, K. Jóźwiakowski, T. Piechota, Energy Conversion from Biomass to Hydrogen and Methane, 4th International Conference on Materials Engineering for Advanced Technologies, London, England, 27 - 28 June 2015, 654 - 657

24. A. Binkiewicz, The possibility of increasing the solar radiation flux using tracking systems, PE. 4, 18 - 20 (2011)

25. G. Jastrzębska, A. Bugała, Modeling the distribution of solar radiation on two-axis tracking plane for the photovoltaic conversion, Energies 8, 1025 - 1041 (2015)

26. F.M. Al - Naima, R.S. Ali, A.J. Abid, Solar tracking system. Design based on GPS and Astronomical Equations, IT-DREPS Conference \& Exhibition, Amman, Jordan, 29 - 31 May 2013, 1 6

27. F.M. Al - Naima, R.S. Ali, A.J. Abid, Design and implementation of a smart dual axis sun tracker based on astronomical equations, European Conference on Renewable Energy Systems (ECRES), Antalya, Turkey, $17-28$ September 2012

28. https://cms.transport.gov.pl (Ministry of Infrastructure and Development)

29. A. Bugała, G. Frydrychowicz - Jastrzębska, Energy balance for tracking systems in photovoltaics for local urban conditions - part II, PUT Academic J. 79, 63 - 69 (2014)

30. A. Bugała, G. Frydrychowicz - Jastrzębska, The UNIPEDE method of assessing electric energy generation costs in photovoltaic systems, PE. 12, 68 $-71(2014)$ 